\title{
Introducing magnesium sulphate for the management of pregnancy induced hypertension
}

The Safe Motherhood Demonstration Project

Follow this and additional works at: https://knowledgecommons.popcouncil.org/departments_sbsr-rh How does access to this work benefit you? Let us know!

\section{Recommended Citation}

"Introducing magnesium sulphate for the management of pregnancy induced hypertension," Safe Motherhood Policy Alert. Nairobi: Population Council, 2005. 


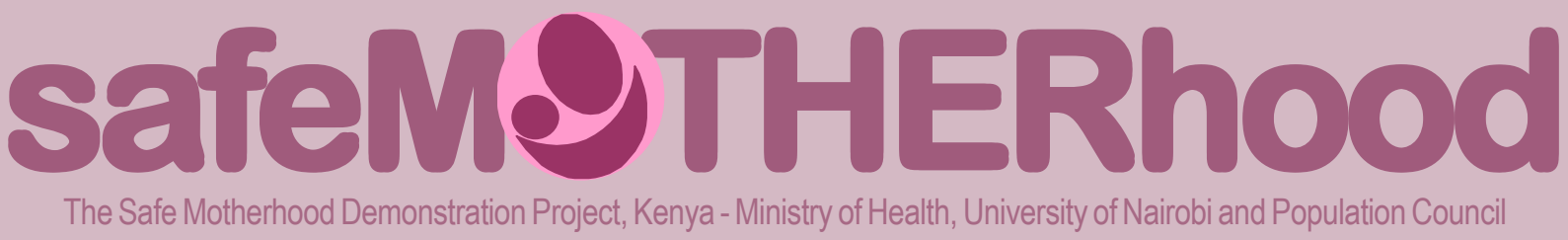

\section{Introducing Magnesium Sulphate for the Management of Pregnancy Induced Hypertension}

\begin{abstract}
Clobal studies ${ }^{1}$ have demonstrated that using Imagnesium sulphate (MgSO4) to manage hypertensive disease in pregnancy, reduces morbidity and mortality due to severe pre eclampsia and eclampsia, one of the five direct causes of maternal death. Major signs of pre eclampsia/eclampsia include high blood pressure, protein in the urine, swelling of the feet, hands and face leading to convulsions (fitting) and coma.
\end{abstract}

Women are not always given anti hypertensives to control the high blood pressure and Diazepam is often the only drug used to control eclamptic fits. However this is a sedative and not an anticonvulsant. MgSO4 on the other hand does not sedate pregnant women and they are alert throughout.

Many countries have been slow to introduce $\mathrm{MgSO} 4$ to the detriment of women's health. Hypertensive disease in pregnancy (Eclampsia) is the second most frequent direct cause of maternal death in Western Province, Kenya at $16 \%$ after haemorrhage $(22 \%){ }^{2}$ In one district hospital all women admitted during 2003 with eclampsia died. There are also critical gaps ${ }^{3}$ in health care provider knowledge, skills and practice in management of eclampsia.

In Essential Obstetric Care and Life Saving Skills training the use of $\mathrm{MgSO} 4$ is advocated and many health care providers know about it in theory but the drug is difficult to obtain and is not part of the essential drugs list available to public health facilities.
Emergency resuscitation trays in maternity units do not always have essential components required: patella hammer (for testing reflexes in patient on $\mathrm{MgSO} 4$ ), calcium gluconate (antidote to MgSO4) and uristix to detect protein in the urine.

Although the use of MgSO4 was introduced successfully to the Maternity Unit at Kenyatta National Hospital, Nairobi in 2001, there has been no systematic introduction of the drug across the country. Generally the only facilities utilising MgSO4 are those supported by development partners and some mission hospitals.

In response to health care managers and providers request in Western Province to be trained in the use of MgSO4, a two-day practical training programme was developed.

\section{Training}

The main objective for the On Job Training was to ensure that participants had specific skills of preventing and managing severe pre eclampsia and eclampsia. In addition the necessary equipment, supplies and $\mathrm{MgSO} 4$ were made available to the facilities where health care providers were trained. Laminated flow-charts illustrating the administration of the drug were distributed for display in the maternity units.

During support supervision two months after the two day training the following were found: 
- 33 out of $44(75 \%)$ of maternity staff interviewed were comfortable using $\mathrm{MgSO} 4$

- 9 out of $15(60 \%)$ of eclamptic mothers had received $\mathrm{MgSO} 4$

- All 6 mothers admitted to PGH with severe pre-eclampsia were treated successfully with $\mathrm{MgSO} 4$

- Twenty-nine mothers admitted with severe pre-eclampsia in the other hospitals did not receive $\mathrm{MgSO} 4$ as providers were only using it for patients who were convulsing. More $\mathrm{MgSO} 4$ was made available and further OJT rectified this.

- There were no adverse effects reported on mothers who received $\mathrm{MgSO} 4$

- $\quad$ Staff who had attended the training reported that they now preferred to use $\mathrm{MgSO} 4$ for managing patients with preeclampsia and eclampsia.

\section{Challenges}

The main challenges

to implementing a

programme such as this include:

- Reluctance of some senior health care providers to introduce the drug in their facilities due to lack of up to date information

- Ensuring essential drugs, supplies and equipment always available

- Continuous education to ensure newly deployed staff are conversant in use of $\mathrm{Mg}$ SO4

- Late referrals from the community;

\section{Policy Implications}

For Magnesium Sulphate to become the routine drug of choice for the management of pregnancy-induced hypertension, this information must be disseminated and clarified at all levels but specifically at the facility level and the drug must be placed on the Essential Drug List. The following issues will need to be included in the RH policy:

- Magnesium Sulphate for the management of PIH to be licensed

- Magnesium sulphate to be manufactured in Kenya - within hospitals or institutions regulated to do so.

- Advocacy at all levels to inform women, families and communities on effectiveness of drug

- Ensure effective Focussed Antenatal Care to detect signs of pre-eclampsia early

- Ensure equipment and supplies are available for prevention of HIP specifically BP machines and uristix (for detection of proteinuria) at all levels of health facility.
${ }^{1}$ WHO 1994

${ }^{2}$ Population Council, MOH, UoN 2004 SMDP Western Province Approaches to providing quality maternal care in Kenya report

${ }^{3}$ Population Council, MOH, UoN Baseline Survey 2002 